Supplement of Saf. Nucl. Waste Disposal, 1, 205-207, 2021

https://doi.org/10.5194/sand-1-205-2021-supplement

(c) Author(s) 2021. CC BY 4.0 License.

Supplement of

\title{
Transdisciplinary research on repository safety: challenges and opportunities
}

Klaus-Jürgen Röhlig et al.

Correspondence to: Klaus-Jürgen Röhlig (klaus.roehlig@tu-clausthal.de)

The copyright of individual parts of the supplement might differ from the article licence. 


\section{Transdisciplinary research on Repository Safety: challenges and Opportunities}

Session 3c - Herausforderungen und Lösungen bei der Transdisziplinarität in der Endlagerforschung

Marcel Ebeling ${ }^{1}$, Klaus-Jürgen Röhlig ${ }^{1}$, Anne Eckhardt ${ }^{2}$, Peter Hocke ${ }^{3}$ and Pius Krütli

${ }^{1}$ Institute of Disposal Research (IELF), Clausthal University of Technology

2 risicare $\mathrm{GmbH}$

3 Institute of Technology Assessment and Systems Analysis (ITAS) at KIT

4 Transdisciplinarity Lab, Eidgenössische Technische Hochschule (ETH)

Interdisciplinary research symposium on the safety of nuclear disposal practices - November the 10th, 2021 


\section{Introduction on TRANSENS and TAP SAFE}

- Project TRANSENS

- from $11 / 2019$ to $10 / 2024$

- first TD research project under the aspect of nuclear waste disposal in Germany

- disciplines from engineering, natural science to social science and humanities

- linking science and society

- Four working packages, EDU \& TD research - HAFF, SAFE, DIPRO, TRUST

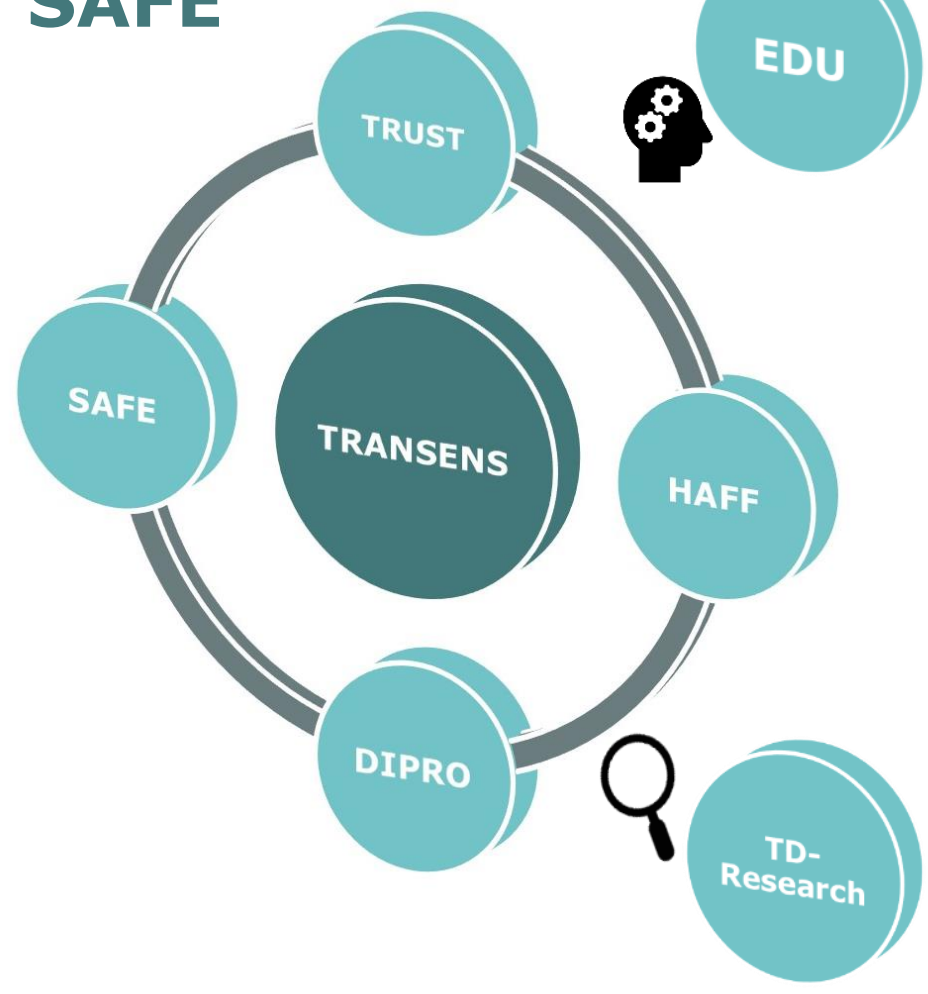




\section{TU Clausthal}

\section{What do we want to achieve in TAP SAFE?}

- Safety Case (SC): Established tool and basis for decision-making in repository programs (based on a variety of safety assessments).

- But also: Criticism of approaches, procedures and standards, which can become relevant in the German site selection process (Standortauswahlverfahren).

\section{Is an optimization of the SC possible/necessary?}

- If so: Scope? Design?

- Focus of stakeholders and interested people?

- Is the very complex SC suitable for TD research? 


\section{TU Clausthal}

\section{What is a Safety Case?}

- Safety Case $(I A E A)$ = "The Safety Case is the collection of scientific, technical, administrative and managerial arguments and evidence in support of the safety of a disposal facility [...]" IAEA (2012)

- Primarily documentation, but also methodology

- Demonstrates compliance with the legally specified protection objectives and safety requirements (in Germany: Ordinance on Safety Requirements for the Disposal of HighLevel Radioactive Waste)

- A Safety Case can have many names e.g.:

- USA: total system performance analysis

- Germany/Switzerland: Sicherheitsnachweis, Sicherheitsuntersuchung, Sicherheitsbericht

- France: Dossier de sûreté 


\section{TD-Research in TAP SAFE}
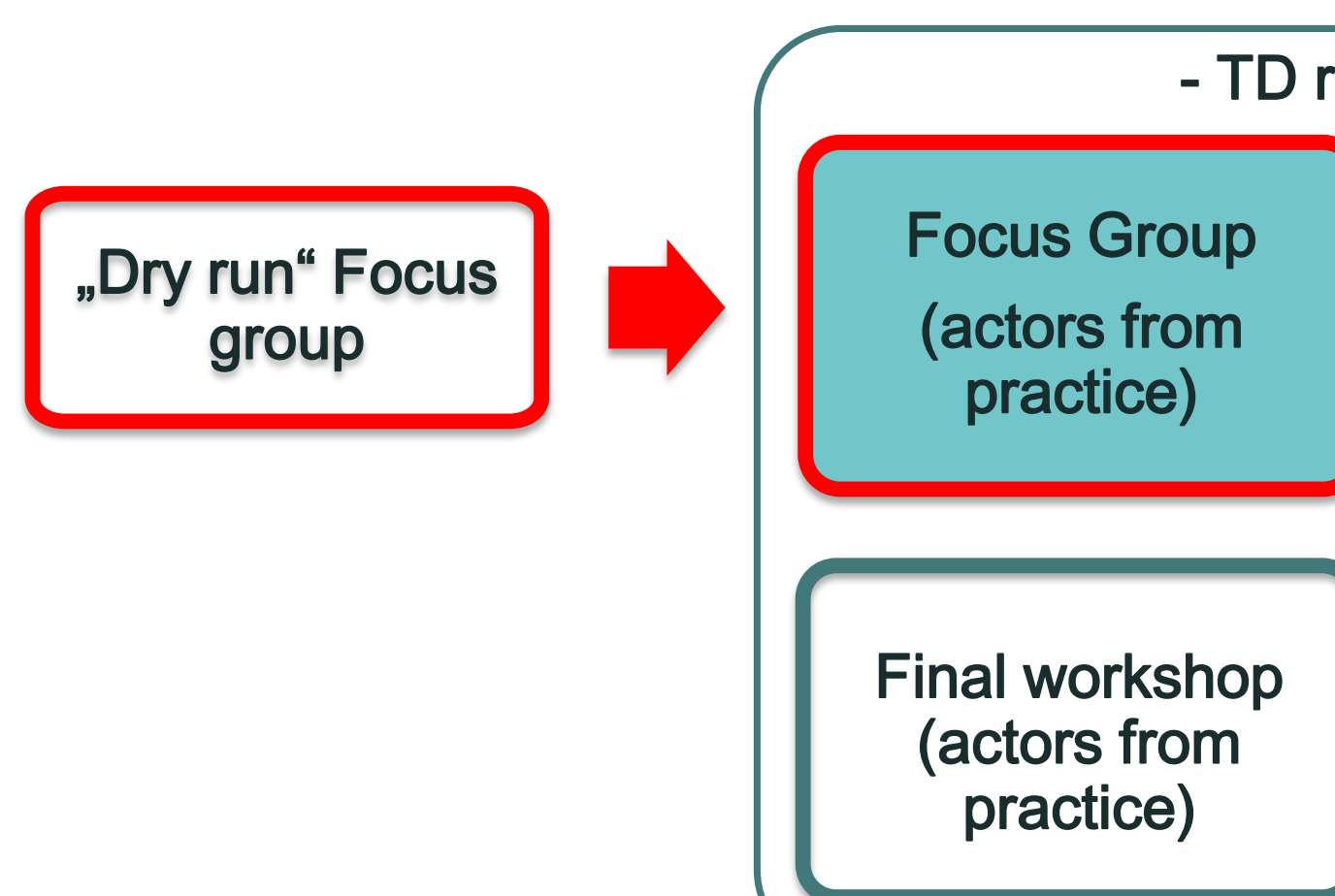


\section{Issues discussed}

- What are your personal experiences in relation to the SC?

- What can the SC prove? What can the SC definitely not do?

- What bothers you about the SC?

- What level of safety should be aimed at?

- Separation of the group into breakout rooms:

- How can ritualized procedures be changed?

- How can a discourse on safety be co-created? 


\section{Results (1/2)}

- Ritualised procedure in the SC

- E.g. FEP (Features, Events and Processes) lists or numerical simulations have "taken on a life of their own".

- SC tools are no longer sufficiently questioned

- Communication problem due to inaccessibility

- The giant amount of information and documentation poses a great difficulty

- Documentation: Multi-level system (oriented towards communication goals / target groups) possibly promising

- Comprehensible, central chain of argumentation

- Separate document vs. "Thinking about communication at the same time"

- Better use of electronic documentation systems, digital SC in the near future 


\section{Results (2/2)}

- Assessment period and the term "Nachweis" (German for "proof")

- "hubris", "unrealistic", discredits SC

- Terms like "proof" or "evidence" are perhaps unfavorable. Safety cannot - in the literal sense - be proven $\rightarrow$ Terms like "safety report" might be better

- SC produced by experts; scrutinized by experts (review)

- Opening necessary?!

- Experts not involved in the process often difficult stakeholders $\rightarrow$ how do you deal with this?

- Taking a closer look at whether the integration and coordination processes between the different SC modules need to be improved 


\section{TD-Research in TAP SAFE}

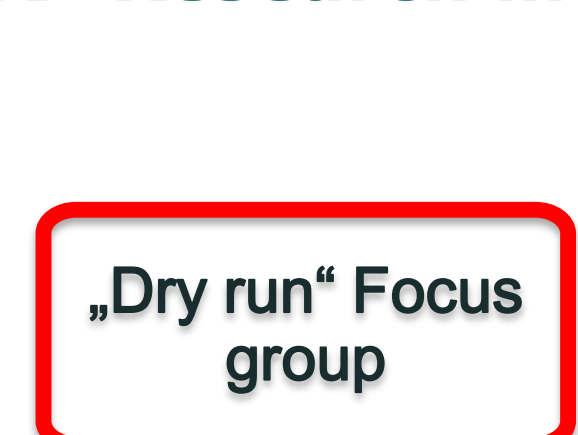

IHi:.: TRANSENS

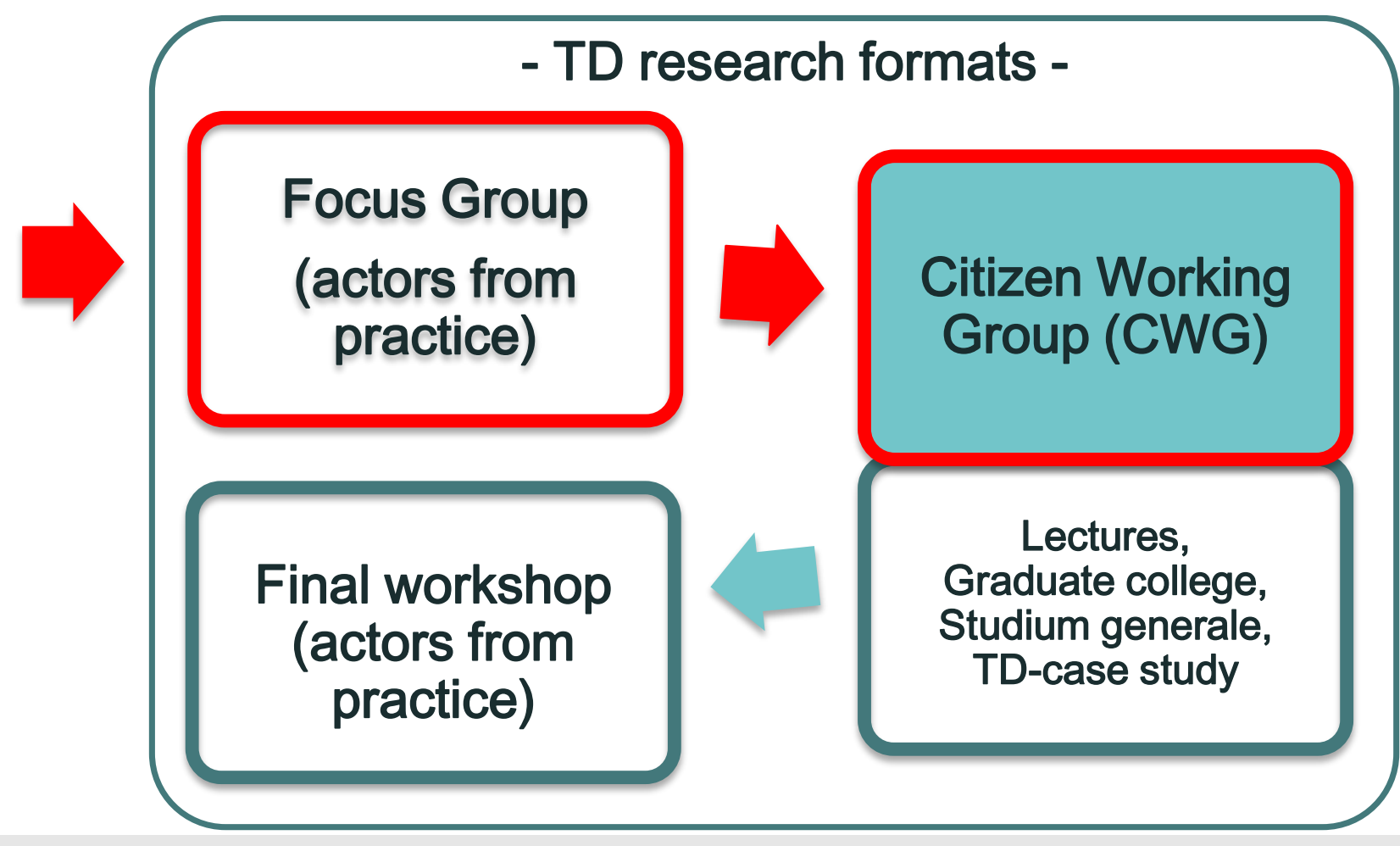

Interdisciplinary research symposium on the safety of nuclear disposal practices Nov. 10th, 2021 


\section{TU Clausthal}

\section{SAFE CWG meetings - overriding goals}

- Substantial input on the content and communication of SAFE's work on the Safety Case in the sense of an 'extended peer review'. Supporting this:

- Explorative investigation to what extent the concept of SC can be made understandable to a population group and which formats of exchange between scientists and population representatives are suitable for this purpose; learning effect on communication on the part of SAFE scientists.

- Promoting the ability to ask constructive questions on specific and general aspects of the SC

- CWG provides input for the optimization of the SC (communication and content) 


\section{CWG cooperation schedule}

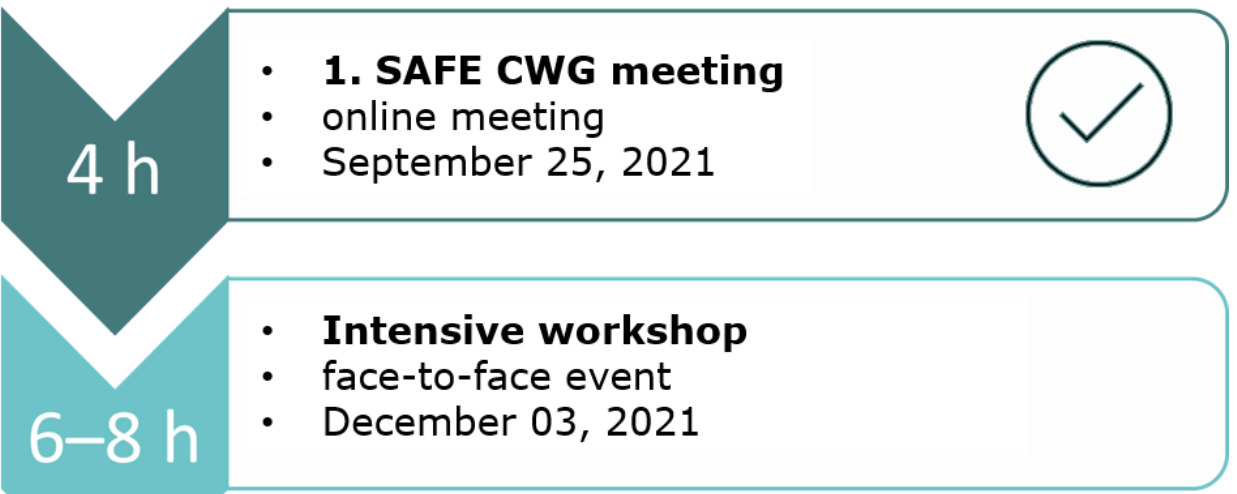




\section{TU Clausthal}

\section{1st SAFE CWG meeting - Goals}

- Convey knowledge (factual knowledge/overview knowledge) and promote questioning skills

- Clarify goals and expectations, co-design with a view to reducing complexity

- Generate interest in the topic and identify subjects the CWG is particularly interested in

- Formation of the volunteer group for the "Intensive Workshop".

- Getting insights for designing Intensive WS

- What kind of preparation material is necessary? 


\section{1st SAFE CWG meeting - Results}

- Identification and development of three work themes:

1. SC and container/canisters incl. material science, geotechnical barrier \& scenarios

2. practical look at: FEP (Features, Events, and Processes), scenarios, exemplary view

3. handling uncertainties, models, presentation of results 


\section{2nd SAFE CWG meeting (planned)}

$>$ Practical look at: FEP, scenarios, exemplary view

- Lead management: GRS

- Workshop with practical examples and exercises, e.g. working with flipcharts

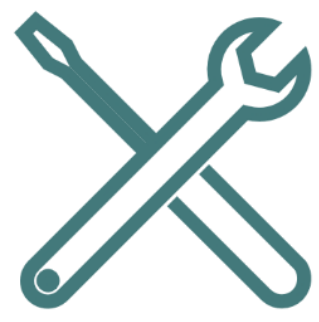

- Main topics:

- View on a FEP database

- Work with selected FEP, influence on initial barriers (scenarios).

- What FEP can YOU think of?

- Review: What could be achieved? 
 \\ TD work following the CWG meetings}

- Graduate Academy at TUC (mid-2022)

- Was identified as necessary $\rightarrow$ adaption during the project

- Utilisation of CWG and focus group results

- Greater focus on technical issues

- Offers in the Studium Generale and TD case study

- Ways to present simulation results

- Further development of the ReSUS platform

- Conclusion Workshop with CWG and actors from practice

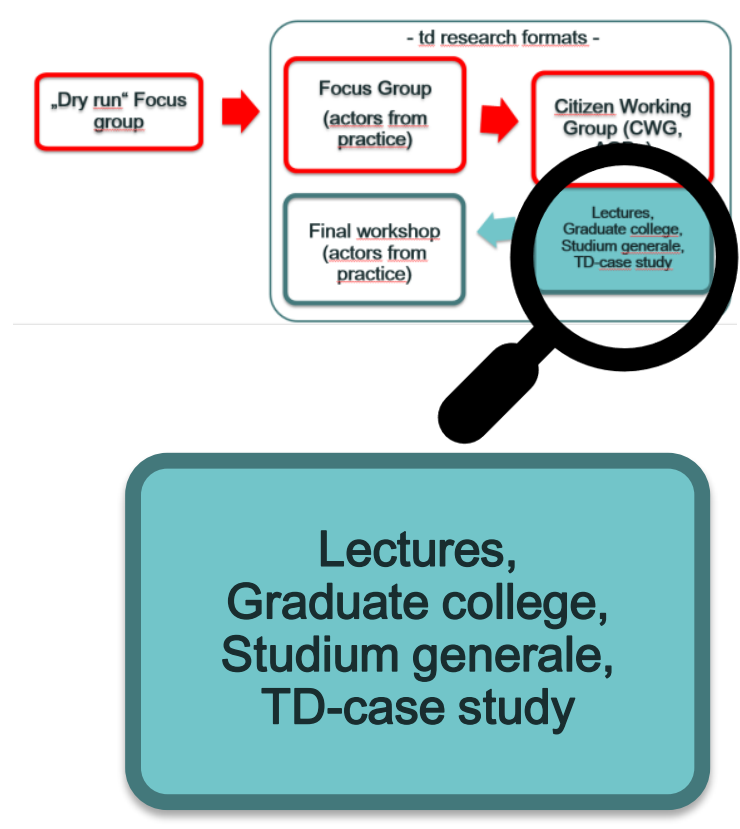


